Short communication

\title{
Comparative study of growing stock of Melghat forests under different silvicultural prescriptions
}

\author{
Saipun Shaikh ${ }^{1,2}$, Lalji Singh ${ }^{2}$ and Amit Kalaskar ${ }^{1}$ \\ ${ }^{1}$ Maharashtra Forest Department, Maharashtra, India \\ ${ }^{2}$ Department of Forestry, Indira Gandhi Krishi Vishwa Vidyalaya, Raipur, Chhattisgarh, India \\ *Corresponding Author: saipunshaikh@ mahaforest.gov.in \\ [Accepted: 23 December 2019]
}

[Cite as: Shaikh S, Singh L \& Kalaskar A (2019) Comparative study of growing stock of Melghat forests under different silvicultural prescriptions. Tropical Plant Research 6(3): 521-523]

\section{INTRODUCTION}

Melghat forests are scientifically managed forests since British era. As per Joshi (1974) scientific management begins in 1880. The art and science of managing forest crop is called as Silviculture. The area is one of the production forestry areas which supplies legal timber to adjoining as well as distant habitations. The area is divided in 1293 compartments for management purposes. The main areas of production forestry are Jarida, Taora and Dharani. The standing timber volume on forest floor is termed as Growing Stock (GS). As elaborated by Ramprakash (2006) the entire forest area is divided in Working Circles (WC) for purpose of management as per species and terrain suitability. Tending operations are inter-culture operations in forestry aimed to obtain vigorous GS. The 'coupe' is equi-productive area demarcated for felling. The objectives of study are, i. To perform statistical comparison of different working plan treatments and ii. To study the impact of management practices on growth pattern of forests.

The protection Working Circle has given no prescriptions being steepness of topography. The gradient does not alllow any tending and thinning operations, hence the growth is not accelerated as compared to worked coupes. It is again important from soil conservation point of view that protection WC (PrWC) kept un-tended. Management of Protection WC mainly resembles to management of wildlife areas where timber harvesting no coupe working is done. The improvement working circle (IWC) is next level of working where malformed timber poles are selected to carry out where improvement fellings, which are primarily done to retain good form of growth.

\section{MATERIALS AND METHOD}

The total area of Melghat landscape is $2969 \mathrm{~km}^{2}$ the area divided in the wildlife area of Melghat Tiger Reserve and Melghat Territorial Forest Division. The area of territorial divisions is divided in working circles (WC) as per the management suitability. The three main Working Circles are considered as treatments being Working Circles are specific treatments and a silvicultural prescription and as well as the tree species is in bound main source of variation. The silvicultural treatments are IWC (Improvement Working Circle), SCI (Selection cum Improvement), TPWC (Teak Plantation Working Circle) are three silviculturally separate treatments. Apart from this, SCI of 2 divisions namely East and West Melghat Divisions taken as separate treatment. TPWC kept in abeyance for non-availability of data.

Based on available working plans and forest resource survey (FRS 2010) records the total Growing Stock in Melghat Forests is quantified through periodic enumerations by FRS team. The periodic data is well maintained in forest records available in statistical wing of departmental headquarters. The FRS uses a systematic line plot sampling technique with random start technique. The FRS surveys recently follow guidelines as per Forest Survey of India (FSI 2002) with some field level modifications The 1:50,000 scale Survey of India toposheet is

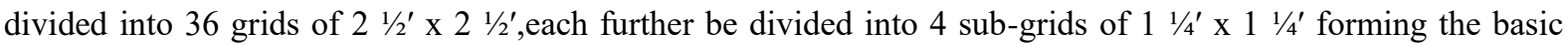
sampling units. Two of these sub grids were randomly selected and corresponding sub grids in all the $2 \frac{1 / 2^{\prime}}{\mathrm{x}} 2$ $1 / 2$ ' grids selected to form the sample. The intersection of diagonals of such sub-grid was marked as centre of plot on the map. At the centre of selected sub grid a plot of 0.36 ha area i.e. $60 \mathrm{~m} \times 60 \mathrm{~m}$ was selected by FRS team 
and enumeration like girth and height are made to work out volume of standing growing stock (GS). For SCI method the criteria of exploitable girth is considered which means the girth above which trees are considered silviculturally matured for harvest.

\section{RESULTS AND DISCUSSION}

The composition of growing stock was seen changing considerably with management practices. The comparative growth difference is drastically seen in different working circles (WC). Tending is high in comparison with protection WC. The forests where comparatively inferior growth is seen and where exploitable girth is not available is slowly made exploitable by executing improvement fellings. The GS/ha reported in IWC was $50.22 \mathrm{CuM}$, which is considerably less as compared to well-stocked selection cum improvement (SCI), where GS/ha was $64.90 \mathrm{CuM}$. We may say this is the transition phase of management to make unworkable forests workable in long terms. The working plan prescribes such improvement as forestry being a long gestation enterprise. Selection-cum-improvement (SCI) is most common practice seen adopted in Melghat working plans as well as many other working plans in India. The system is compatible with natures ease and supporting biodiversity conservations. The silvicutural observations are comparable with observations of Tewari (2017) where the regime of thinning to improve GS volume is elaborated in detail. The Melghat landscape which mainly dominated by Melghat Tiger Reserve (MTR), the working plan prescriptions like SCI are quite supporting to adjoining wildlife management in MTR. The SCI system does not expose forest floor hence soil is conserved to the great extent. Only exploitable diameter class is removed to open up canopy and allow sunlight and nutrients to upcoming regeneration. The composition of GS is depicted in figure 1.
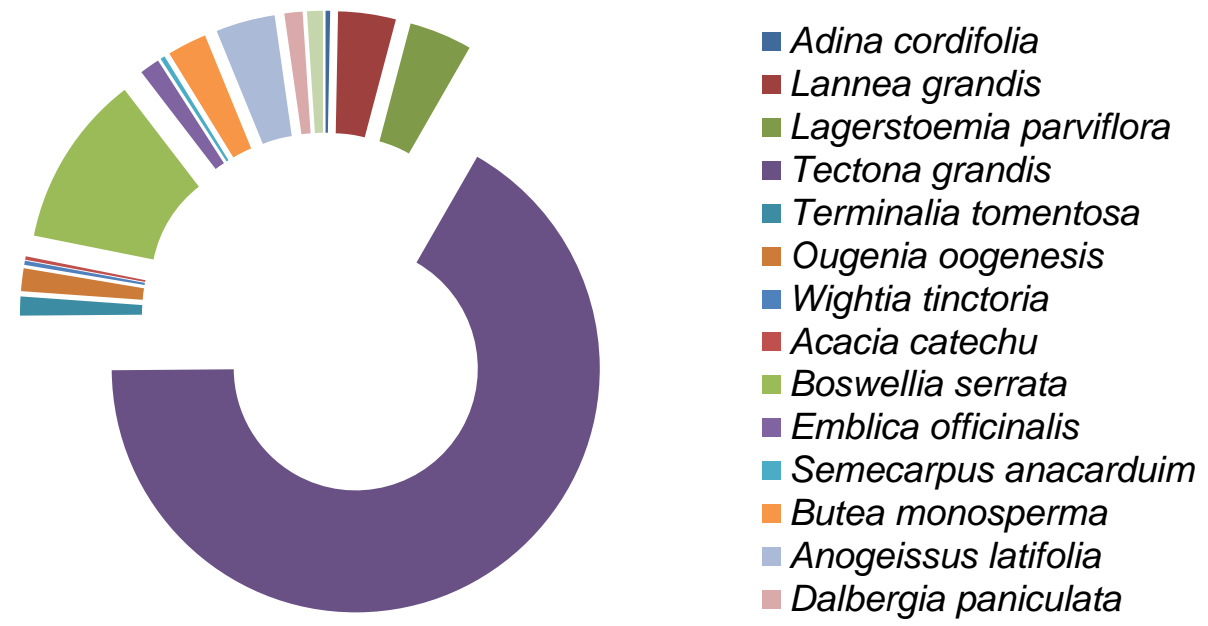

Figure 1. Growing Stock composition in Melghat forests.

The Melghat growing stock is dominated by Teak (Tectona grandis L.f.) followed by Salai (Boswellia serrata Roxb. ex Colebr.), Lannea gradis and Lagersroemia spp as depicted from the figure 1.The Analysis of Variance (ANOVA) conducted for GS observations and found that the silvicultural treatments show considerable difference in terms of GS. Also the significant variation between species is also analysed in table 1 . Between groups variation is attributable to silvicultural treatments while within-group variation is attributable to tree species.

Table 1. Analysis of variance (ANOVA) conducted for GS observations.

\begin{tabular}{|c|c|c|c|c|c|c|}
\hline Source of Variation & $S S$ & $d f$ & $M S$ & $F$ & P-value & F crit \\
\hline Between Groups & 27.6293 & 2 & 13.81465 & 0.147902 & 0.862814 & 3.142809 \\
\hline Within Groups & 5884.446 & 63 & 93.4039 & & & \\
\hline Total & 5912.075 & 65 & & & & \\
\hline
\end{tabular}

\section{CONCLUSION}

The extreme difference found in growing stock (GS) depending on working circle. Selection cum Improvement- SCI has good GS stock as compared to IWC. Though Teak Plantation Working Circle -TPWC not evaluated in present study for want of data, there are chances to get more GS/ha as prescribed by Tewari (2017). Between-group variation is attributable to silvicultural treatments while within-group variation is attributable to tree species. FRS data has tremendous potential to be used in forestry research. Rather than doing repeated enumeration or relying on indirect measurements like satellite data, universities shall collaborate with forest departments for long term utility of data. 


\section{ACKNOWLEDGEMENTS}

The help provided by forest \& wildlife wing by preparing good database is highly acknowledged, guidance of Dr. Pravin Chavan, CCF Amravati.

\section{REFERENCES}

FRS (2010) Forest Resource Surveys 2004 to 2007 in Maharashtra State, Vol. VI. Government of Maharashtra Publication, pp. i-vi \& 62-66.

FSI (2002) The manual of instructions for field inventory. Forest Survey of India- FSI publications, Dehradun (Uttaranchal), pp. 09-13.

Joshi PP (1974) Working plan for the Melghat Forests: East \& West Melghat Divisions. Government Prints \& Book Depot, Nagpur, 114 p.

Ramprakash (2006) Forest Management. International Book Distributors, Dehra Dun, Uttaranchal, India, pp. 01-142.

Tewari VP (2017) Enhancing carbon retention through improved forest management. Indian Forester 143(9): 928-930. 